\title{
Curriculum enquiry about community engagement at a research university
}

\author{
C. J. G. Bender \\ Faculty of Education \\ University of Pretoria \\ South Africa \\ e-mail: gerda.bender@up.ac.za
}

\begin{abstract}
The curriculum should be paramount in the academic field since the university uses curricula to put its ideas into effect. The curriculum field and community engagement are both comprehensive at universities but research on curricular community engagement (CCE) is imperative. Curriculum theory was used as a theoretical framework for this article, with community engagement regarded as a method, process, programme and practice in higher education. The purpose of this article was firstly to apply analytical philosophical enquiry to the conference proceedings and focus groups (data resources) at two higher education conferences (2006 and 2007) so as to improve concept development and interpretation of CCE. Secondly, it was aimed at using theoretical enquiry to create a conceptual and curriculum scheme for CCE. Thirdly, I consider the meaning of the concept development and interpretation and conceptual scheme for CCE for the Faculty of Education at my research university. The basic curriculum problem for future research is: How do programme and module outcomes, content (syllabus), collaborative partnerships (engagement), and community engagement practice interact?
\end{abstract}

\section{INTRODUCTION}

In recent years, there has been increasing pressure on universities worldwide, including those in South Africa, to bridge the gap between higher education and society and to become active partners with communities, leading to 'engaged institutions' which help to reduce inequity (Waghid 2002). Community engagement is a fashionable term that is currently in flux. The initial literature and policy review for this article revealed many old and new claims about what community engagement is (Higher Education Quality Committee (HEQC) 2004a; 2004b, 2004c; HEQC/ JET 2006; JET 2006). This article focuses on the formal and structured academic programmes through community engagement $(\mathrm{CE})$, embracing the transformation of the curriculum at universities in South Africa.

Many university policies, documents, annual reports, and websites mention CE, curriculum-related $\mathrm{CE}$ and service-learning as virtually synonymous, but these terms are not interchangeable. In some cases, pre-existing practices such as experiential education, community service, community development, community-based education, 
clinical practicals, practica, community outreach and even service-learning have simply been renamed community engagement. This shift in terminology may or may not have precipitated a substantial change in the ways of seeing, being and acting associated with these pre-existing practices, yet the extent to which the term CE is being used is still significant as a measure of the diffusion - and perhaps confusion - relating to my topic.

For nearly a decade we have grappled at universities with various concepts and terms relating to community service and academic programmes that would best describe what we actually do, and attempted to construct a framework that seems appropriate to the university's vision, mission, strategic thrusts, and objectives for promoting the scholarship of engagement. Yet we have neglected to explore and investigate community engagement from a curriculum point of view.

The impetus for this article is the potential that CE holds for transforming the curriculum, and for developing or revising the curricula to be more responsive to the national and regional context (public accountability). This would redefine scholarship and involve society in a productive discourse about the role of higher education in South Africa. An exploration of and investigation into the integration of $\mathrm{CE}$ in the curriculum are required in the South African context. In a previous article I explored the conceptual models for CE at universities in South Africa, and indicated the knowledge gaps for a conceptual and theoretical framework for Curricular Community Engagement (CCE) (Bender 2008a). In another article I investigated the management and infrastructure to initiate and promote CCE (Bender 2007). However, so far I have given little attention to reporting on my curriculum studies on $\mathrm{CE}$ in higher education.

The curriculum is one of the most important factors in the academic field of higher education, as curricula put into effect the ideas of the university. In addition, curricula realise the values, beliefs and principles relating to learning, understanding, knowledge, disciplines, individuality, and society (Barnett and Coate 2005).The HEQC (2004d, 20) states that curriculum has narrow and broader definitions. Narrow definitions are limited to formal descriptions of the academic offerings of specific programmes or the whole range of programmes on offer. Broader definitions might involve the intentional plan(s) and design(s) for learning across an institution and what students and lecturers actually accomplish and experience.

Le Grange (2006) posits that the curriculum is a neglected area in discourses on higher education. He suggests that higher education curriculum matters should be more critically debated in the public sphere, and that these matters should not be the narrow concern of individual or groups of academics. In this article I take up his suggestion and open a discourse on CCE. The curriculum in higher education and community engagement are both exceedingly complex fields. Nevertheless, experience in other equally complex fields, such as the human mind, offers some encouragement for curriculum researchers.

I wish to use the following two questions as a guideline for this article: first, the concepts that might serve to guide CCE (analytical enquiry); and second, how 
statements relating to structural elements, strategies, and action guidelines should best be formulated to convey the overall conceptual and curriculum scheme posited for CCE (theoretical enquiry). This study employs curriculum theory as a theoretical framework (Ornstein and Hunkins 2004) and community engagement as a method, process, programme, and practice in higher education (cf. Bender 2004). I regard the curriculum in higher education as a field of study and action intended to be educationally transformative through a value-added approach that is outcomeoriented, and also to educate citizens for social justice and democracy so that they can play an active role in society. As the enquirer, I cannot control what is examined nor do I have controlled experiments in a double-blind design for curriculum studies and community engagement. I believe that theory holds fields of study together, making it possible to interpret the information available.

After describing the curriculum research methodology, the remainder of this article is divided into three main sections: In the first section I apply analytic philosophical enquiry to the conference proceedings of two higher education conferences (2006 and 2007) with the aim of understanding and improving the concept development and interpretation for CCE. In the second section I apply theoretical enquiry to create a conceptual and curriculum scheme (structure and components) for CCE with strategies and plans of action to clarify the essence of CCE. In the third section I consider the possible meaning of concept development and interpretation, and conceptual scheme for CCE for the Faculty of Education at a research university in South Africa.

\section{CURRICULUM RESEARCH METHODOLOGY}

Best and Kahn (2003) point out that there are three basic approaches to understanding educational phenomena, in this case CCE: the historical (what was), the descriptive (what is), and the experimental (what might be). Descriptive-analytical research was the method selected for this article as it focuses on what is and I believe this is the currently the best option for the field of CCE in higher education.

As this study is on curriculum research, firstly I used an analytical philosophical enquiry and secondly a theoretical enquiry into higher education curriculum and programme development relating to community engagement (Short 1991). Analytical philosophical enquiry aims at understanding and improving the sets of concepts. Two especially significant types of enquiry in analytical philosophical enquiry in this study are concept interpretation and conception development. Concept interpretation enquiry seeks adequate concrete interpretations of the concepts we use to formulate curricular studies and programmes (Short 1991). By contrast, conceptual analysis is used for gaining a sound understanding of the ordinary meaning of a concept such as CCE (Short 1991).

The conceptual analysis of CCE used two main data sources. The first was the data obtained from focus group interviews with the special interest group members for $\mathrm{CCE}$, and the ten conference papers by academics in the stream for CCE at the 10th Biennial Conference of the South African Association for Research and 
Development in Higher Education (SAARDHE) hosted by the Faculty of Education at the University of Pretoria, South Africa (July 2007). The second data source was the conference proceedings on Community Engagement in Higher Education, and specifically the report on the responses of the 35 academics during three workshops (with focus groups) on community engagement through teaching and learning (Fourie and Bender 2007). This article uses the concept curricular community engagement (CCE) instead of community engagement through teaching and learning, for reasons which will become clear in my discussion below. The last-mentioned Conference on Community Engagement in Higher Education, hosted by the Higher Education Quality Committee (HEQC) of the Council on Higher Education (CHE) and the Community - Higher Education - Service Partnerships (CHESP) initiative of JET Education Services (JET), was held in September 2006 in Cape Town, South Africa (HEQC/JET 2007). These conference papers and proceedings were used in an attempt to obtain academics' conceptualisations, conceptual structures and theoretical frameworks regarding $\mathrm{CCE}$, to determine various types of CCE, community-engaged teaching and learning and other related concepts.

Conception development is enquiry designed to develop, construct, and defend a conception (Short 1991, 27-28). I refer to this as concept development, in an attempt to develop and justify a defensible view of what CCE comprises. The aim of conception development in this study was the analytical task of discovering the meanings participants attach to concepts such as CE, CCE, community engagement through teaching and learning; collaborative partnerships (engagement) and scholarship of engagement. I also wished to examine whether it would be necessary to reformulate, reshape or replace the concepts (Short 1991; Tight 2003).

Theoretical enquiry was the second enquiry used in this study. Its purpose in curriculum research is to create conceptual schemes for making understandable the essential nature and structure of curricular phenomena and processes. When developing a curriculum, we necessarily adopt and employ some conceptual scheme and a specialised vocabulary and language. Likewise, when undertaking an enquiry about a curriculum, I have to adopt and employ a conceptual scheme and ask questions, such as: How can such conceptual schemes be formulated and used in a research university? (Short 1991).

Theoretical enquiry about the curriculum is an interdisciplinary, creative and cooperative endeavour. The theoretician or researcher in this case must also have wide experience of various curricular phenomena, processes and challenges in order to appreciate what has to be conceptualised. This immersion in curricular realities informs one's perceptions and is the basis for judging which aspects are fundamental and which perspectives are central to making a curriculum understandable.

For the data analysis I used qualitative or non-frequency content and the methodology of conceptual analysis (Fraenkel and Wallen 2000; Tight 2003; Short 1991). All of the textual data (participants' responses during focus groups, papers, and conference proceedings) was analysed by means of interpretative content and 
conceptual analysis in a mainly inductive fashion to create a conceptual scheme for CCE (Strauss and Corbin 1990).

\section{CONCEPT DEVELOPMENT AND INTERPRETATION FOR CURRICULAR COMMUNITY ENGAGEMENT (CCE)}

This section reports on the concepts of development and interpretation, based on my analytical philosophical enquiry, which could guide CCE at other universities in South Africa. Based on the textual data, the transcript analysis and overarching set of codes, as well as the more refined analyses of a smaller number of texts and transcripts, the participants indicated that they accepted as a premise that CCE was embedded in Boyer's (1996) different functions of scholarship, namely the scholarship of discovery, teaching, application and integration. They assumed that the engaged university reflected the institutional alignment that Boyer (1996) identifies as the 'scholarship of engagement', that is, scholarship that connects the rich resources of the university with our most pressing social and civic challenges. The participants indicated the following concepts and interpretations as the most important in discussions about CCE and are integrated with the conceptual scheme in the next session. Only the concepts CE, CCE and related concepts are discussed in this section in an attempt to develop and justify a defensible view of what CCE comprises.

\section{Community engagement}

The HEQC (2004a) gives the following definition of community engagement (CE), which is used as a basic reference in most universities in South Africa and was also accepted and used by participants at both conferences. CE refers to the

... initiatives and processes through which the expertise of the institution in the areas of teaching and research are applied to address issues relevant to its community. CE typically finds expression in a variety of forms, ranging from informal and relatively unstructured activities to formal and structured academic programmes addressed at particular community needs and some projects might be conducive towards the creation of a better environment for Community Engagement and others might be directly related to teaching, learning and research (CHE HEQC 2004a, 19 \& 26).

The definition does not attempt to constrain other definitions of engagement, but rather to acknowledge the full range of engagement activities undertaken by South African universities. This means that a research university can reshape the definition and concept to fit the university's context, culture, and functions of scholarship.

\section{CCE and related concepts}

As a basic concept of development and interpretation for community engagement through teaching and learning, the CHE/HEQC and JET publication, Service-Learning in the curriculum. A resource for Higher Education Institutions was provided to the 
workshop participants and focus groups at the HEQC/JET (2007) (Bender, Daniels, Lazarus, Naude and Sattar 2006). These participants focused on Chapter 2 in the book: A theoretical and conceptual framework for service-learning. This resource was also used as the conceptual framework for the papers on CCE at the SAARDHE conference (2007), consequently research has been done in South Africa on the conceptual and theoretical aspects of service-learning. However, service-learning is only one type of CE through teaching and learning. The following are the main aspects of the concept of development and interpretation enquiry: Dewey's (1963) experimentalism, and its emphasis on the principles of experience, enquiry, and reflection, are recognised as the key elements in a theory of knowing in CE through teaching and learning. The experiential learning theory of Kolb (1984) builds on the foundation of Dewey's (1963) experiential education philosophy. Kolb regards experience as paramount for learning, and recognises four important elements as key to learning: concrete experience, reflective observation, abstract conceptualisation, and active experimentation and action learning. The fourth element is linked to Dewey's (1963) pragmatism and Kolb's (1984) experiential learning theories, which hold that learning can only be of value if applied to real-life situations.

By means of analytical conception development enquiry, I conceptualise CCE as a curriculum, teaching, learning, research and scholarship activity which engages academic staff, students and community service agencies/organisations in mutually beneficial and respectful collaboration. Their interactions address communityidentified needs, deepen students' civic and academic learning and enrich the university's scholarship. CCE is an indicator of the intersection with and cross-cutting models of $\mathrm{CE}$ and is a benchmark for $\mathrm{CE}$ (see discussion below). CCE is one of the main categories of community engagement at some universities in South Africa. As the focus in these universities is on the integration of $\mathrm{CE}$ into the curricula of formal academic programmes, they also refer to this as community-engaged teaching and learning. However, the concepts of 'engaged teaching' and 'engaged learning' should be examined to develop conceptual structures and schemes. The participants at both the conferences related to CCE, namely SAARDHE (2007) and HEQC/JET (2006), supported the idea that $\mathrm{CE}$ in teaching and learning embraces curricula which reflect South African and African circumstances and challenges, and gives opportunities for lifelong learning, professional development and community development.

CCE can be subdivided into various types, such as: community service (national service); community-based education; internships (clinical practice or practicals); work-based learning; co-operative education; community-based learning; servicelearning; community-based projects; and community outreach (cf. Naude 2006 for a discussion of these concepts).

Universities should move towards intra-institutional consensus on different types of CCE, so that they can adopt one or more types. Since universities have different contexts, cultures, and challenges, they may engage in different types of CCE. It would be necessary to debate the different types at institutional level to progress towards 
gaining consensus on understanding CCE and the different types of CCE for a particular higher education institution / faculty / department / programme or module.

The conceptual analysis indicates that the participants recognised two main categories of $\mathrm{CE}$ : curricular and non-curricular community engagement. However, only CCE is relevant to this article.

\section{A CONCEPTUAL AND CURRICULUM SCHEME FOR CURRICULAR COMMUNITY ENGAGEMENT}

This section discusses a conceptual and curriculum scheme (structure and components) for CCE based on theoretical enquiry, integrating all the concepts from the analytical enquiry (see previous section) and adding strategies and plans of action to clarify the essence of CCE at higher education institutions in South Africa.

\section{Conceptual schemes for Community Engagement at HEls}

During the September 2006 conference on Community Engagement in Higher Education mentioned above, and in the conference proceedings of the HEQC/JET (2007), three models of community engagement were proposed, namely the silo, intersecting and cross-cutting models. The three models of CE can be summarised as follows: Silo model: The university has three roles - teaching and learning, research and $\mathrm{CE}$ - and pursues each of these relatively independently of the others. Generally, $\mathrm{CE}$ in this model is confined to community outreach and student/staff volunteerism. Intersection model: the university has three roles - teaching and learning, research and $\mathrm{CE}$ - and acknowledges that there is some intersection among the three roles, and where there is an intersection it innovates service-learning whereas community outreach and volunteerism continue as separate activities. Cross-cutting model: the university has two fundamental roles - teaching and learning, and research - and defines $\mathrm{CE}$ as a fundamental idea and perspective, which must inform, animate and be integrated with most of its teaching and learning, and research activities (Bender 2008a). Each university was advised that, for whatever reasons, it could adopt whatever model it deemed appropriate in relation to its vision, mission, strategic thrusts and objectives, and the values, context and paradigms for CE.

In the theoretical framework of this study I have replaced the concept model with conceptual schemes, creating a new conceptual scheme for making community engagement - and specifically CCE and its processes - more understandable at a research university.

\section{Institutional and Faculty level: a conceptual scheme for CCE}

The university has three core functions - teaching and learning, research, and community engagement - and acknowledges that there is some intersection among them (see Figure 1). Where the roles of teaching and learning, and community engagement intersect, there is Curricular Community Engagement (CCE). Where 
research and community engagement intersect, there is Research-related Community Engagement (R-CE). Where there is no intersection, there is non-Curricular Community Engagement (Non-CCE), for example volunteerism and community projects, which proceed as separate activities. I focus only on CCE and R-CE, leaving non-CCE to future articles.

This conceptual scheme with the structure and components of CCE is an emergent structure that frames community engagement as an irreducible and essential element of the existing functions and notions of a university (Figure 1). This conceptual scheme emerged from interactions with academics, conceptual analyses of conference proceedings, and from the findings and interpretation of my institutional and curriculum research. The process is the structural operation of the scheme, representing activity within and among levels, groups, and individuals. The conceptual scheme can be applied to or integrated in various disciplines (fields of study) at interdisciplinary, institutional or faculty level.

The conceptualisation of $\mathrm{CE}$ assumes that research and teaching/learning ultimately involve engagement with the community, whether direct or indirect, and irrespective of whether the impact is educational, social, economic or cultural. This conceptual scheme includes, for example, teaching/learning and research activities and projects in various formal academic programmes. The distinguishing feature of this intersectional conceptual scheme of CE in universities is that it does not require or presuppose a radical shift in the universities' core functions and activities. Instead, it assumes that universities are invariably already engaged in various ways with communities. To the extent that education is a fundamentally social and relational practice, which is embedded in communities, I concur with this view. I note, however, that although at least some form of engagement is inevitable in the contemporary contexts of teaching/learning, research, and community engagement, the extent of consciously perceived and actively nurtured social responsibility does vary considerably. If $\mathrm{CE}$ constitutes a central part of the transformation of the research university, it should respond to the needs of society, contribute to the common good and social responsibility, and educate staff and students in social justice and democratic citizenship.

\section{Scholarship of engagement as the ultimate outcome of CCE}

The scholarship of engagement, briefly discussed above, is regarded in the conceptual scheme as the ultimate aim of CCE, as shown in Figure 1 where teaching/learning, research and community engagement intersect or infuse. Ernest Boyer's (1996) ideas have influenced the conceptual interpretation of the scholarship of engagement in the scheme. Going from good to great at universities involves understanding and putting into effect the scholarship of engagement:

The academy must become a more vigorous partner in the search for answers to our most pressing social, civic, economic and moral problems, and must reaffirm its historic commitment to what I call the scholarship of engagement (Boyer 1996, 11). 


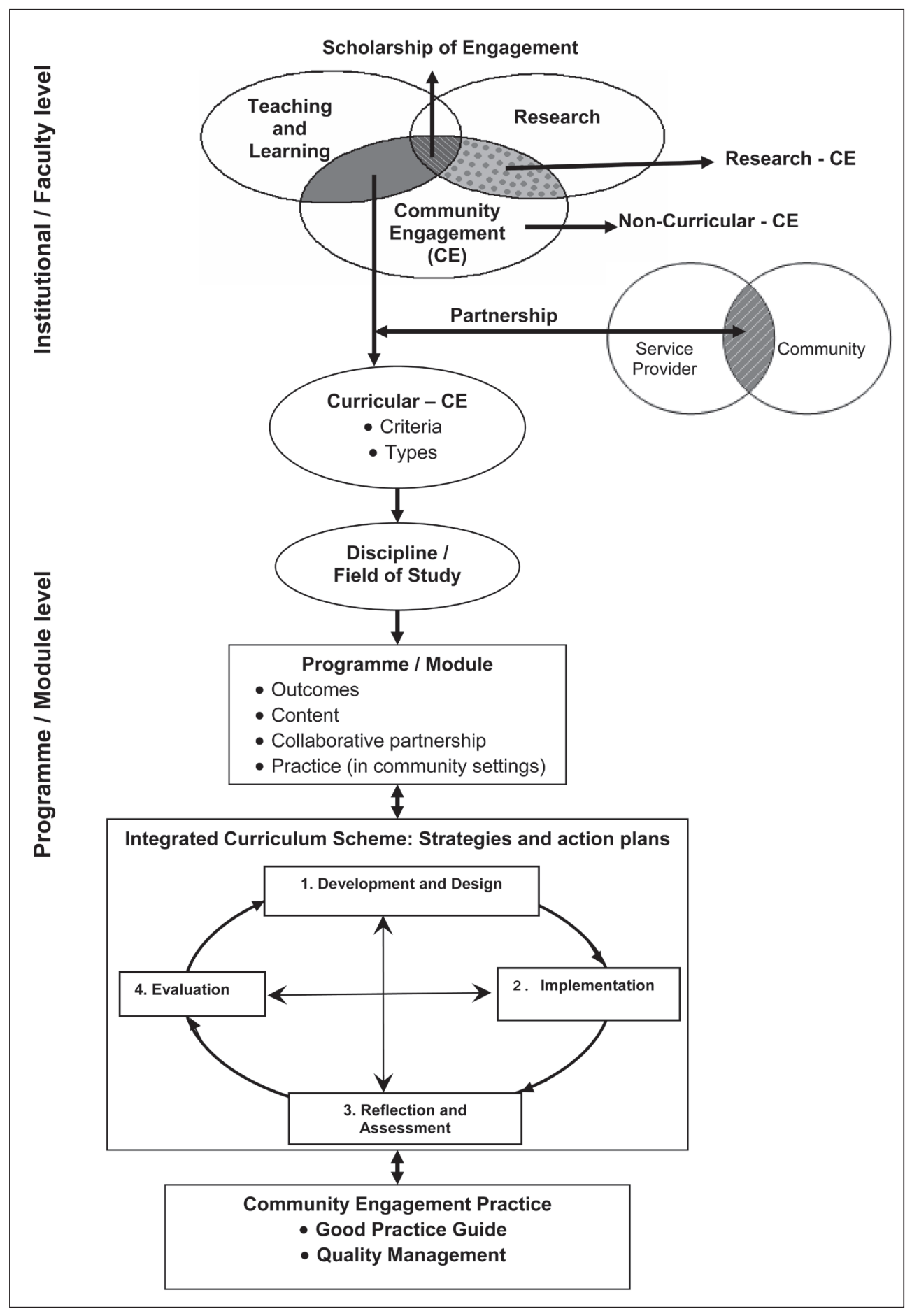

Figure 1: A conceptual and curriculum scheme for Curricular Community Engagement 


\section{Partnership (engagement): Community, Higher Education Institution and Service Provider (CHESP)}

Engagement (a component of the scheme) is the partnership between a university's knowledge and resources with those of the public, service and private sectors so as to enrich scholarship, research and innovation; enhance the curriculum and learning and teaching; prepare educated, engaged citizens; strengthen democratic values and civic (social) responsibility; address critical societal issues; and contribute to the public good. As Brukhardt, Holland, Percy and Zimpher $(2004,9)$ suggest: 'Partnerships are the currency of engagement - the medium of exchange between university and community and the measurement of an institution's level of commitment to working collaboratively.'

The CHESP scheme identifies three partners forming a triad: the service agency or provider, the community and the higher education institution (including the academic staff and students) and is the preferred conceptual scheme for engagement (Bender et al. 2006). Communities are the specific, local, collective interest groups that participate in a university's CE activities and are regarded as partners with a full say in the identification of service needs and development challenges. They also participate in defining the community service and development outcomes; identifying the relevant assets at their disposal, and evaluating the impact of $\mathrm{CE}$. Communities also contribute substantially to the mutual search for sustainable solutions to challenges and service needs in the South African context. The members of such communities are generally the disadvantaged, materially poor residents of underserviced urban, peri-urban, or rural areas. In many instances these communities can be accessed most efficiently through service sector organisations, such as government or state departments, as well as non-governmental, community-based or faith-based organisations (Bender et al. 2006).

\section{CCE in the different disciplines at faculty, programme and module level}

At both national and institutional levels, there is a need for flexible and streamlined processes of programme approval. Unnecessary delays or bureaucracy should be avoided in the interests of responsiveness to community needs as they are identified. These processes relate to the approval of new programmes and amendments to programmes, so that curricula can be made responsive to communities. The university's ideas are put into action through the curricula. In addition, the values, beliefs and principles relating to learning, understanding, knowledge, disciplines, the individual and society, are realised through curricula.

Curriculum-based (credit-bearing) community-engaged modules and programmes can be achieved when $\mathrm{CE}$ is infused into the teaching/learning function of all disciplines in a research university. Community-engaged teaching and learning, that is, an engaged pedagogy, cannot be integrated casually into the curriculum or simply be added on to the existing responsibilities of academic staff. It requires a significant 
investment in planning, time, and finances to reshape and restructure existing and new modules and, ultimately, to test and revise these new forms of teaching. Important components or dimensions for CCE programme and module development and design are the programme or module outcomes, content selection (syllabus), collaborative partnership with the service agency and community (engagement), and educational practice in the community setting or community engagement practice.

\section{Criteria for CCE}

When the participants, representing both conferences (2006 and 2007), were asked which type of CCE or community-engaged teaching and learning might be most valuable for a specific context and university, they proposed that communityengaged teaching and learning should encompass curriculum-based (credit-bearing) educational experiences; have a significant component of relevant and meaningful service with the service agency and community (needs and assets identified by the community); enhance student learning; include purposeful civic learning by inculcating, for example, social responsibility; provide opportunities for structured reflection by students and promote a scholarship of engagement (Fourie and Bender 2007).

At this stage, only service-learning meets the participants' criteria for communityengaged teaching and learning at universities in South Africa (Bender 2007). I suggest we should rather use the concept of community engagement practice and have community-engaged teaching in a programme or module as a teaching methodology, and community-engaged learning as a learning strategy.

Engaged-learning pedagogies share the assumption that knowledge is actively coconstructed by educators, learners and the community members with whom we work, and is labelled the 'strands of reform' in higher education. These 'strands' include service-learning, community-based research, integrative learning, collaborative learning and problem-based learning (cf. Swaner 2007). Engaged pedagogies must no longer be exceptions but become the building blocks of a fundamental transformation in the way academics 'teach' and students 'learn' in higher education. When engaged pedagogy and its philosophical base are shifted from the periphery to the centre of educational practice, institutions will progress toward establishing larger cultures of engagement which can fulfil the promise of engaged learning (Swaner 2007).

\section{Types of CCE and practices in academic programmes}

As discussed in the previous section, CCE can be subdivided into various types such as: community service; community-based education; teaching practice; internships; clinical practice or practicals; learnerships; work-based teaching and learning; cooperative education; community-based learning; service-learning; communitybased projects; and community outreach (Fourie and Bender 2007). Universities should stimulate academic discourse and debate on the pedagogies underpinning these types of CCE and practices. 
The following discussion is a summary, guided by some of the participants' responses (SAARDHE 2007 and HEQC/JET 2006 conference), my interpretations of these responses and my experience with the training of academic staff at my university, regarding the specific strategies required and plans of action for integrating community engagement in the curriculum.

\section{A curriculum scheme for $C E$ in the curriculum: strategies and actions}

The curriculum scheme for integrating $\mathrm{CE}$ in the curriculum or the integrated curriculum model as discussed in the book, Service-Learning in the curriculum: a resource for Higher Education Institutions (Bender et al. 2006) provides a 'how to' guideline for academic staff on integrating CE in the curriculum. When using the integrated curriculum scheme, all strategies (development and design; implementation; reflection and assessment, and evaluation) and actions (steps) are followed, programme outcomes formulated, learning outcomes formulated for the module, the syllabus or module content is specified, reflection and assessment are aligned, quality management is ensured, and there is compliance with the requirements of legislation and institutional curriculum and programme development. Curriculum alignment, that is, the principle of ensuring that the purpose of a programme (or module) is supported by the content selection, learning outcomes, teaching-learning methods, educational practice such as CE practices and the assessment methods for delivering it, is ensured by implementing the integrated curriculum scheme (see Bender et al. 2006, Chapters 3 and 4 for a detailed discussion of the integrated curriculum model).

\section{Community Engagement practice and quality management}

Quality assurance in the core functions of universities - teaching and learning, research, and CE - involves four evaluative stages, namely (1) input, (2) process, (3) output and impact, and (4) review. These evaluative stages should form the basis of the framework for assuring the quality of CCE; in other words, the same quality assurance strategies and criteria should be applied to all three core functions. Quality assurance is crucial to ensuring that $\mathrm{CE}$ retains its academic credibility regarding learning facilitation and skills development. The university ought to conduct its own programme of ongoing quality audits to monitor the processes of learning, educational practices, and skills development.

A good practice guide and self-evaluation instruments for managing the quality of service learning is a publication intended to help universities manage the quality of service-learning (or any other type of CCE) at an institutional, faculty, programme and module level (HEQC/JET 2006). The HEQC recognises this guide, emanating from the extensive work done through the CHESP's monitoring, evaluation and research programme, as the official guide to quality assurance (QA) in this field and is used in institutional audits (Lazarus 2007). 
The virtue of any viable scheme lies in its conceptual clarity, its perceived fit with reality, and the compelling nature of its structure and justification. The value of a conceptual scheme is not the supposed correctness of its choice of concepts and language, but its utility and efficacy, which can only be judged in practice (Short 1991). In the next section I apply the conceptual scheme for CCE to the Faculty of Education at a research university.

\section{CCE AT THE FACULTY OF EDUCATION AT A RESEARCH UNIVERSITY}

Although my discussion concerns a particular Faculty of Education at a research university, it is relevant and can be applied to any other faculty at the University of Pretoria (UP) and also to other South African universities.

This section is based on an internal audit conducted on the status quo of community engagement in the Faculty of Education at UP in March 2008. This Faculty has three fundamental functions - teaching and learning, research, and community engagement. The Faculty uses the Council for Higher Education's definition of CE as reference (HEQC, 2004a, 19), adjusting it to suit the context. In the Faculty, CE is regarded as the continuously negotiated collaborations and partnerships between the Faculty and the constituencies with which it interacts, such as schools (preschool, primary and secondary schools), service agencies, government and non-government organisations, with the purpose of building and exchanging the knowledge, skills, expertise, and resources required to develop and sustain society. Therefore, with CE, the Faculty employs the scholarly expertise and resources of the academic staff and students to render mutually beneficial services to local, regional and national communities, in a collaborative partnership. CE is defined as a fundamental idea and perspective, which are integrated with teaching and learning, and research. Consequently, CE and the knowledge base of teaching and learning, and research, become mutually enriched (scholarship of engagement). The Faculty's mission includes a commitment to ensuring that all undergraduate and postgraduate students, as part of their learning experience in professional education and training, have the opportunity to participate in curriculumbased and research-based community engagement.

Although the Faculty classifies CE as Curricular Community Engagement (CCE); Research-Related Community Engagement (R-CE) and Non-Curricular Community Engagement (Non-CCE), this article focuses only on CCE as its context. The scholarship of engagement is regarded as the aim of CCE and is part of the Faculty's strategic plan. The Faculty has adapted and implemented the conceptual scheme for CCE (see Figure 1) for its context. I describe only one discipline or field of study, namely Education, briefly discuss the programmes and modules with CCE, and report on what is (descriptive approach to curriculum research and enquiry).

\section{CCE and practices in academic programmes}

CCE integrates CE activities and projects in the curricula of formal undergraduate and postgraduate academic programmes in the Faculty of Education at UP. In a 
mutually beneficial and respectful collaboration, communities participate, or could potentially participate, in the Faculty's CE activities in partnership with community service agencies/organisations/government/non-government organisations and sponsors to promote teaching, learning and the scholarship of academic staff, students and schools. This collaboration addresses community-identified needs and assets, deepens students' civic and academic learning, enriches the scholarship of the university and improves the quality of education and community life.

The Faculty has different types of CCE, such as school-based teaching practice and teaching internships, internships and practica, school-based projects, communitybased projects, academic service-learning (ASL), and work-based teaching practice and learning.

Undergraduate: four modules from the second to fourth year of study - schoolbased teaching practice and internships in all the B.Ed. (foundation, intermediate, senior phases and further education and training) programmes. The modules Early literacy, Language across the Curriculum and Practical Remedial Education are community-based projects, ensuring that all undergraduate teacher-training students have the opportunity to participate in community engagement activities and projects in their second and third academic years. All second-year undergraduates taking the module Language across the Curriculum have to spend 15 hours on the community project that focuses on tutoring learners in the English medium in disadvantaged communities, such as the township schools in Mamelodi, several orphanages and students' other individual projects.

Postgraduate: the Faculty is involved in various CCE activities, and has state-ofthe-art facilities for practical training in the B.Ed. (Hons.) (Educational Psychology) and M.Ed. (Educational Psychology) programmes, presenting the academic servicelearning, practica and internships at various service agencies, schools, and community sites.

The career guidance module, with a practicum in M.Ed. (Educational Psychology), includes the Ngilandi Project - a collaborative effort between the Department of Educational Psychology and the Ngilandi Secondary School in Mpumalanga. Second-year students do their practical training in career guidance with Grade 9 learners, as well as educators, at this rural school.

The B.Ed. (Hons.) (Adult and Community Education and Training) and the coursework M.Ed. (Education for Community Building) programmes contain four modules with academic service-learning. The outcome of the community education project is to place the school in the centre of the community and also regard it as a 'learning community'. B.Ed. (Hons.) students do 25 hours of service-learning at selected primary and secondary schools and service agencies in the Pretoria and Mamelodi area.

The Postgraduate Certificate in Education (PGCE) has a school-based teaching internship. The Postgraduate Certificate in Higher Education (PGCHE) has two modules with work-based teaching practice and learning, as well as a module on 
the theory and practice of Community-Based Learning for academic staff at higher education institutions.

In the Faculty of Education I undertook a curriculum research study on the history of CE and CCE (from 1908-2008) and reported the findings in a conference paper entitled Century pathways of change for Curricular Community Engagement at $U P$ (Bender 2008b). The third phase of the curriculum research study, referred to as the experimental (what might be) by Best and Kahn (2003), will be stipulated in the Faculty of Education's strategic plan (2008-2011) and encompass how the programmes and modules have or should have integrated the curriculum scheme (see Figure 1), the application of the Good Practice Guide and how the quality of $\mathrm{CCE}$ and $\mathrm{CE}$ practices are managed.

\section{CONCLUDING THOUGHTS}

South African academics interested in CCE have a golden opportunity to develop significant undergraduate and postgraduate programmes. The integration of teaching/ learning, research and community engagement provides diverse and rich benefits for a research university and communities. CCE is an opportunity to conduct serious and scholarly work (Bringle and Hatcher 2005). CCE will be most significant when it results in the scholarship of engagement that integrates the functions of scholarship, namely teaching, discovery, application, and integration.

The findings of this curriculum research study with its analytical and theoretical enquiry into community engagement are significant because they reveal the four main dimensions of CCE: purpose or outcomes for the academic programme and module, content (syllabus), collaborative partnership (with a service provider and community), and educational CE practice. The study of CCE deals with the manifold interactions among these four dimensions, as well as the nature of each dimension. However, the curriculum is based on the interaction, not on the individual parts. Future research should determine the interaction of the programme with module outcomes, content (syllabus), collaborative partnerships, and community engagement practice. A complete map of the field would be enormously complex and comprehensive, since it could include many differing specifics. Curriculum developers tend to ignore this complexity, choosing to emphasise one or two aspects of the whole, as if these were the whole. If we want to discover why things are - the meanings - we must begin by acknowledging that the curriculum derives its facts and meanings from their context, and that the study of CCE consists of facts in context. The broader the context, the more profound the meanings.

The challenge for CCE is the complexity of the field and the fact that most of the factors influencing the results of my efforts to teach, are beyond my control. This compels me to rely, not on certainties, but on often weak probabilities and logical consistencies.

The descriptive-analytical and theoretical research undertaken for this study does not have the appeal of experimental research, but it may well be the best option 
at present in the CCE curriculum field. I included a case study of the Faculty of Education at a research university to demonstrate how a conceptual scheme (theory) could be partially applied in practice. In higher education we do not control most of what we deal with; we can forecast, and uncertainly, only short-term phenomena. There has been little or no close observation of educational endeavours such as community engagement activities and projects, or community engagement practices, and no studies on CCE practice. Typically, we observe only gross phenomena, such as a low throughput of students at universities. There has been a revival of interest in teaching methods as well as some systematic observations of teaching, but we still lack teaching methodologies in CCE, in the different disciplines, and especially in community-engaged teaching. There is still a gap between learning more about students' experiences and close observation of a group and the individual students involved in CCE practice.

CCE encompasses theory and practice, so it must respond to the appeals of educational action researchers that curriculum enquiry should deal with practice and curricular settings and be done by practitioners. I suggest that CCE practitioners should conduct action research aimed at improving CCE practice, gaining a better understanding of CCE practice and the different types of CCE practice in order to improve the context (service agency and community) of CCE practice. As we work in collaborative partnerships with service providers and communities, our CCE practitioners should involve the service agency and community members in curriculum research and thus conduct cooperative and participatory action research (PAR), aimed at enhancing the scholarship of engagement.

The growth in community engagement as a method, process, programme, and practice in the past five years has provided a foundation for sustained expansion. We have to create and evaluate the conceptual schemes and theoretical foundations of CCE in practice and include lecturers, students, service providers and communities in our research. This also entails developing best practices for CCE, managing its quality and expanding the horizons at universities in South Africa.

\section{REFERENCES}

Barnett, R. K. and K. Coate. 2005. Engaging the curriculum in higher education. Open University Press: Society for Research into Higher Education.

Bender, C. J. G. 2004. Community development. In Keys to Educational Psychology, eds. I. Eloff and L. Ebersohn. Cape Town: UCT Press.

- 2007. Pathways to change for integrating Community Service-Learning into the core curriculum. Special Issue of Education as change - Community service-learning 11 (3): 127-142.

Bender, Gerda. 2008a. Exploring conceptual models for community engagement at higher education institutions in South Africa. Perspectives in Education 26 (1): 81-95.

Bender, C.J.G. 2008b. Century pathways of change for curricular community engagement at the University of Pretoria. Paper presented at the EDUVATE 2008 Conference: Education 
Innovation Quest: A Century in the service of knowledge. 25-27 June, University of Pretoria, Pretoria.

Bender, C. J. G., P. Daniels, J. Lazarus, L. Naudé and K. Sattar. 2006. Service-learning in the curriculum: A resource for higher education institutions. Pretoria: Council on Higher Education/ Higher Education Quality Committee/ JET Education Services. Available at: http://www.che.org.za/documents/d000121/index.php.

Best, J. W. and J. V. Kahn. 2003. Research in education. Boston: Library of Congress Cataloguing-in-Publication data.

Boyer, E. L. 1996. The scholarship of engagement. Journal of Public Service and Outreach (1):11-20.

Bringle, R. and J. Hatcher. 2005. Service learning as scholarship: why theory-based research is critical to service learning. Acta Academica (3):24-44.

Brukardt, M. J., B. Holland, S. L. Percy and N. Zimpher. 2004. Calling the question: is higher education ready to commit to Community Engagement? A Wingspread Statement Conference Report. Milwaukee: University of Wisconsin, Milwaukee Idea Office.

Dewey, J. 1963. Experience and education. New York: Collier.

Fourie, M. and G. Bender. 2007. Report on concurrent workshop Community Engagement through Teaching and Learning. In Higher Education Quality Committee/JET Education Services, South Africa. 2007a. Community engagement in higher education. Proceedings of the CHE-HEQC/ JET-CHESP Conference on Community Engagement in Higher Education: 3-5 September 2006. Pretoria, South Africa: Council on Higher Education. Available at: http://www.che.org.za/documents/d000153/index.php.

Fraenkel, J. R. and N. E. Wallen. 2000. How to design and evaluate research in education. Boston, Ma: McGraw-Hill.

Furco, A. 1996. Service-learning: A balanced approach to experiential education. In Expanding boundaries: Service and learning, ed. B. Taylor, 2-6. Washington, DC: Corporation for National Service.

Higher Education Quality Committee, South Africa. 2004a. Criteria for institutional audits. Pretoria: Council on Higher Education.

- 2004b. Criteria for programme accreditation. Pretoria: Council on Higher Education.

- 2004c. Framework for programme accreditation. Pretoria: Council on Higher Education.

—. 2004d. Improving teaching and learning resources. ITL Resource No. 1. Programme planning, design \& management. Programme Review. Pretoria: CHE. Available at: http://www.che.org.za/heqc_cq/teaching_learning/teaching_learning.php.

Higher Education Quality Committee/ JET Education Services, South Africa. 2007. Community engagement in higher education. Proceedings of the CHE-HEQC/ JETCHESP Conference on Community Engagement in Higher Education: 3-5 September 2006. Pretoria, South Africa: Council on Higher Education. Available at: http://www. che.org.za/documents/d000153/index.php.

- 2006. A good practice guide and self-evaluation instruments for managing the quality of service-learning. Pretoria: Council on Higher Education. Available at: http:// www.che.org.za/documents/d000122/index.php.

JET Education Services. 2006. Annual Report 2006. Johannesburg: JET.

Kolb, D. A. 1984. Experiential learning. Englewood Cliffs, NJ: Prentice Hall. 
Lazarus, J. 2007. Embedding service learning in South African higher education: The catalytic role of the CHESP initiative. Special Issue of Education as Change - Community Service-Learning 11 (3): 91-108.

Le Grange, L. 2006. Curriculum: a neglected area in discourses on higher education. South African Journal of Higher Education 20 (2): 189-194.

Naudé, L. 2006. Community engagement through teaching and learning: Introductory notes. Paper presented at the Community Engagement in Higher Education Conference hosted by the CHE-HEQC/ JET Education Services-CHESP, 3-5 September 2006, Cape Town, South Africa. Available at: http://www.che.org.za/documents/d000153/index.php.

Ornstein, A. C. and F. P. Hunkins. 2004. Curriculum: foundations, principles and issues. Boston: Allyn and Bacon.

South African Association for Research and Development in Higher Education (SAARDHE). 2007. $10^{\text {th }}$ Biennial Conference hosted by the Faculty of Education at the University of Pretoria, South Africa.

Short, E. M. 1991. Forms of curriculum inquiry. Albany: State University of New York.

Strauss, A. and J. Corbin. 1990. Basics of qualitative research. Newbury Park: Sage Publishers.

Swaner, L. E. 2007. Linking engaged learning, and well-being and civic engagement: a review of the literature. Liberal Education. Winter:16-25.

Tight, M. 2003. Researching higher education. Berkshire, England: Society for Research into Higher Education and Open University Press.

Waghid, Y. 2002. Knowledge production and higher education transformation in South Africa: towards reflexivity in university teaching, research and community service. Higher Education 42:457-488.

Zuber-Skerritt, O. 2002. The concept of Action Learning. The Learning Organisation 9 (3): 114-124. 